\title{
On the Emergence and Evolution of Economic Complexity
}

\author{
Bernard C. Beaudreau \\ Department of Economics Université Laval Québec, Québec, Canada \\ E-mail: bernard.beaudreau@ecn.ulaval.ca
}

Received January 27, 2011; revised April 12, 2011; accepted April 23, 2011

\begin{abstract}
This paper examines the emergence and evolution of economic complexity, defined as large-scale specialization and exchange (LSSE), within the context of a simple coordination game in which communication and coordination costs (institutions) are modeled explicitly. The commonly held view that complexity in the form of LSSE (pre- and post-industrial society) emerged and evolved spontaneously (i.e. as a Nash outcome) is examined critically. Specifically, it is shown that spontaneous-occurring LSSE equilibria are less likely than coordination-based ones (i.e. with a third party). Various communication and coordination strategies (CCSs) are examined, the results of which are then used to examine three complexity-increasing periods, namely ancient Mesopotamia and the first and second industrial revolutions. It is argued that in addition to technological innovations, all three were characterized by important institutional innovations (CCS) including the birth of laisser-faire and the rise of the modern-day, vertically- and horizontally-integrated industrial conglomerate.
\end{abstract}

Keywords: Specialization and Exchange, Coordination Equilibria, Ancient and Modern History

\section{Introduction}

In the Paleolithic era, economic activity was organized around the tribe/clan with varying degrees of specialization and exchange. Men hunted, defended the tribe/clan from attack and crafted tools, while women collected berries, reared children, and prepared meals/clothing. Roles were defined by a number of factors, from genetics to tradition. With the coming of the first civilizations came a new form of social and economic organization, one based on a greater degree of specialization and exchange. For example, in Mesopotamia, wealth creation and exchange was organized by the local temple. Goods and services were stored and traded within the confines of the temple. The result was a more complex form of social and economic organization similar to modern-day market-based economies, with specialized producers, and specialized traders, the latter operating the equivalent of modern-day stores.

With this shift came an important increase in economic complexity, defined as "the order resulting from the interactions of many heterogeneous agents" $[1]^{1}$.

\footnotetext{
${ }^{1}$ Similarly, Wikipedia defines civilization as "a kind of human society or culture; specifically, a civilization is usually understood to be a complex society characterized by the practice of agriculture and settlement in cities."
}

Producers became highly specialized, and complex exchange emerged in the form of temple-based exchange. This raises a number of interesting, and until now, unanswered questions, namely, why and how did this happen? What prompted the emergence of economic complexity? Was it spontaneous in nature, or was some form of communication and coordination required? If communication and coordination was required, what form did it take?

Another significant increase in economic complexity occurred in the $19^{\text {th }}$ century with the coming of industrialization $[2,3]^{2}$. Tasks that had until then had been performed on a small scale (i.e. home production) were now performed on a large-scale. Overall output increased manifold. With this came a new communication and coordination strategy (CCS) in the form of rules-based laisser-faire, replacing what until then had been a discretion-based CCS (i.e. mercantilism). This raises another set of questions, namely were the two related, and if so, how? Was the shift to a rules-based CCS a cause or an effect? Could the first industrial revolution have occurred

\footnotetext{
${ }^{2}$ For our purposes, economic complexity will be defined as the extent to which goods and services are obtained via exchange, as opposed to autarky. Maximum economic complexity, according to this definition, occurs when the individual is completely specialized, producing one good/service (one task), and acquiring all others by exchange.
} 
within a discretion-based, hierarchical CCS (i.e. mercantilism)?

These questions are important for a number of reasons. For one, they are important historically. What prompted epoch-defining paradigm increases in economic complexity, and what role did communication and coordination strategies play? What were the corresponding institutions? How did they emerge and evolve? Second, they are important theoretically. Can economic complexity increase spontaneously-that is, in a Nash sense-as is commonly believed? Or, is it more appropriately modeled as a coordination game? Third, they are important from a practical point of view. For example, what lessons does the past have to offer to countries intent on moving to more complex forms of economic organization. Lastly, one could argue that a better theoretical and historical understanding of the emergence of complexity and subsequent innovations in complexity is an invaluable input in the current debate over institutions and their role in economic development $[4,5]$.

This paper attempts to address these questions historically and theoretically. Specifically, it examines the emergence and evolution of economic complexity, defined as large-scale specialization and exchange (LSSE), within the context of a Schelling-type coordination game in which communication and coordination costs are modeled explicitly. The results are then used to examine what is largely held to coincide with the emergence and evolution of economic complexity, namely the birth of civilization in Mesopotamia and subsequent innovations, namely the first and second industrial revolutions. The paper is organized as follows. To begin with, we examine the literature on specialization and exchange, both at the firm and economy-wide levels. This provides a segue into the next section which presents our baseline model, consisting of a one-shot Schelling specialization-coordination game [6], involving players who choose between remaining autarkic or specializing. The two resulting Nash equilibria are examined with particular emphasis on the LSSE equilibrium. As the latter is more likely in the presence of a third party (i.e. communication and coordination), we then turn and examine various communication and coordination strategies (CCSs) with particular emphasis on the corresponding costs. Integrating these into the one-shot specialization game provides us with the evolutionary model of economic complexity that is then used to study economic complexity historically. To begin with, we examine the emergence of economic complexity in ancient Mesopotamia, specifically in Sumer and Akkad. This is followed by an account of the first and second industrial revolutions, both of which witnessed a marked increase in economic complexity. Given the role of rules-based CCSs, specifically of lais- ser faire, in industrialization, we examine various aspects of what Karl Polanyi refers to as the "Great Transformation." We conclude with a discussion of our results, and a summary of our findings.

\section{Production Process Complexity and Economic Complexity}

The study of economic complexity is as old as economics itself, dating back in time to the French Physiocrats (e.g. Tableau économique), and to Adam Smith's An Inquiry into the Nature and Causes of the Wealth of Nations. According to Smith, complexity, while being the result of new technologies, notably the steam engine, was determined by the extent of the market. The greater the extent of the market, the greater the overall level of specialization (division of labor) in the economy and, consequently, the greater the level of wealth. Economic complexity, as such, was technology-driven, but market determined. Specialization at the firm level according to Smith required coordination. The latter was the responsibility of the entrepreneur, whose task it was to coordinate parallel and sequential high-throughput, Boulton-Watts rotary-drive powered production sub-processes within the firm. Specialization and mechanization, he argued, were key determinants of productivity growth, as evidenced by the following passage taken from Chapter 1 of "The Wealth of Nations."

The great increase in the quantity of work which, in consequence of the division of labour, the same number of people are capable of performing, is owing to three different circumstances; first, to the increase in dexterity in every particular workman; secondly, to the saving of the time which is commonly lost in passing from one species of work to another; and lastly, to the invention of a great number of machines which facilitate and abridge labour, and enable one man to do the work of many [7].

According to the classics and neoclassics, coordination within the firm was the purview of the entrepreneur. Beyond him/her, coordination would be carried out by markets. Just where in-firm coordination ended, and markets began was not-well understood. Clearly, production sub-processes within the firm were coordinated by the entrepreneur. Anything beyond, it was usually assumed, was left to the market.

The early $20^{\text {th }}$ century witnessed a shift in this frontier, with an increase in hierarchical, in-house coordination in the form of highly vertically and horizontally-integrated firms [8,9]. Increasingly, the invisible hand of the market was being usurped by the visible hand of hierarchy. This raised a number of fundamental questions, questions the profession continues to study to this very day. What happened? Why the sudden reversal of fortunes? After 
all, according to basic theory, markets were superior to hierarchies, or so it was thought. Ronald Coase reframed the question in terms of transactions costs [10], arguing that when transactions costs are high, firms internalize what would otherwise be arms-length transactions. Others, including Oliver Williamson, examined various alternative communication and coordination strategies, the result of which was taxonomy of organizational structures consisting of four such arrangements: market governance, bilateral governance, trilateral governance and unified governance [11]. Market governance is the preferred arrangement in the case of recurrent and non-specific transactions, whereas trilateral governance is used for occasional and medium specific transactions. Unified governance is preferred for recurrent and highly-specific transactions.

The 1990s witnessed a renewed interest in such questions. This, one could argue, owed to a number of developments, including the productivity slowdown, and outsourcing, both of which raised fundamental questions regarding organizational structure. For example, was centralization or decentralization more conducive to innovation and productivity growth? Outsourcing, some argued, signaled the start of a new phase in organizational structure, namely what Richard Langlois referred to as the "Vanishing Hand", namely a shift away from large-scale, integrated industrial conglomerates (hierarchy) back to markets [12].

Gary Becker and Kevin M. Murphy's work on the division of labor, coordination costs, and knowledge was one of the earliest attempts at examining the relationship between the division of labor, coordination and knowledge. Moving away from the Coasian concept of transactions costs, they emphasized coordinating costs, specifically on the in-firm costs of coordinating specialized and highly interdependent activities [13]. Similarly, Thomassen and Lorenzen examined the relationship between coordination mechanisms, specialization of production activities, information and knowledge, and learning processes [14].

Related questions have and continue to be studied in the organizational behavior literature where the focus is on the constrained-optimization approach to modelling the concept of bounded rationality, based largely on costly communication and coordination. According to Timothy Van Zandt, constrained-optimal bounded rationality means that "there are upper limits on agents ability to communicate and to calculate with information in the brain" [15,2]. Put differently, firms face communication constraints and computation constraints, the presence of which affects organizational structure, placing a limit on production process complexity, and as such the division of labor.
This literature has, for the most part, focused on the division of labor in a partial equilibrium setting - that is, from the point of view of the individual firm. Recently, [16-19] examined the "economy-wide" division of labor as a coordination game where firms decide whether to specialize or not based on other firms' strategies and where markets are assumed to exist. Nonetheless, coordination failures are shown to exist. As it turns out, this literature assumes the existence of markets-that is, the problem studied here has already been resolved ${ }^{3}$. There are players (agents) who have specialized in buying, holding and selling merchandize. The merchant's problem (autarky or specialize) is not addressed. A more complete analysis would have producers specializing in the presence of markets (specialized traders), but not otherwise, and the emergence of markets (specialized traders) in the presence of specialized producers. Put differently, a player's decision to specialize would depend on whether other players specialize and whether the relevant trading institutions exist and vice versa.

Surprisingly little attention has been paid to this problem, whether from a historical point of view or a theoretical point of view. How do (have) societies, in their pursuit of economic complexity, solve (solved) this "coordination problem." Did LSSE evolve spontaneously, or was costly communication and coordination required? What were the institutions that allowed for large-scale specialization? Clearly, there were times in the history of civilization (forms of economic complexity) when planning (specialization and exchange) dominated, and others when laisser-faire dominated. For example, throughout much of ancient and modern history, hierarchies dominated (from Mesopotamia to Rome to Medieval Europe); for the past two centuries, laisser-faire has dominated. How and under what circumstances did such LSSE-related equilibria arise? Was the choice of a communication and coordination strategy a cause or effect of epoch-defining technological change? Clearly, the role of CCSs in the development of increasingly complex societies is an important question, historically, theoretically, and practically (i.e. policy wise).

John Hicks, in A Theory of Economic History, published in 1969, raised a similar question, which he referred to as "specialization upon trade," to be distin-

\footnotetext{
${ }^{3}$ In related work, similar questions have been raised. For example, Jeremy Greenwood and Bruce Smith examined the emergence of markets in a world of specialized intermediate goods [20]. Markets, they argue, are a necessary condition for production technologies requiring specialized intermediate goods. Rachel Kranton studied a similar question, namely the emergence of market exchange [21]. Two modes of exchange are considered, namely reciprocal versus large market exchange. Conditions under which large market exchange emerge were derived. Both forms of exchange, however, assume specialization to begin with. Agents can either trade in informal markets (exchange) or in formal markets. An obvious extension would have large-scale specialization and exchange being derived endogenously.
} 
guished from "trading without specialization. [22,23]" Specialization upon trade refers to the Smithian notion of "the division of labor" upon "the extent of the market." In short, the coordination problem referred to earlier. Just how various civilizations solved the underlying coordination problem, he argued, was unknown. Among the possible communication and coordination strategies, he posited, were 1) social gatherings (religious festival, fairs), 2) a command economy, and 3) a mercantile economy. In the case of social gatherings, specialized traders emerged in response to arbitrage opportunities. In the case of a command economy, a "King" or ruler "will be receiving embassies from neighboring chieftains", and will engage in gift-giving. In this case, it is the "king's steward" who, over time, evolved into a merchant. According to Hicks:

The steward who is employed upon this task is already performing, by order, some of the functions of a merchant. If he performs them successfully, so that he is sent back for repeat performances, he will become specialized upon his new activity. He is not an independent merchant, but he is a merchant. He is still a servant of the King; a servant (like other servants) has become specialized upon a particular function. Trading, on behalf of his master, is the function he is called on to perform. [22,30]

Our definition of economic complexity (i.e. LSSE) is similar to Hick's, namely, the presence of specialized producers and specialized merchants. Judging from his list of probable causes, it is likely that various coordination and coordination strategies (CCSs) played an integral part of the emergence and evolution of economic complexity. We now attempt to formalize this process.

\section{Modeling the Emergence and Evolution of Economic Complexity}

In this section, we develop a stylized model of the emergence and evolution of economic complexity, defined as large-scale specialization and exchange (LSSE). To begin with, we examine LSSE in terms of a one-shot Schelling-type coordination game [6] involving three initially-autarkic players $[23,24]$. The results are then generalized to the $n+1$ player case and communication and coordination costs are introduced.

\subsection{The One-Shot Coordination/Complexity Game}

We begin with the baseline case, involving three players $(\mathrm{I}=1,2,3)$ each of whom produces two goods $\left(y_{i}\right.$ and $\left.x_{i}\right)$. Production technology is relatively simple. Player 1 is assumed to have an absolute advantage in the production of $y$; player 2 in the production of $x$; player 3 in nei- ther. In autarky, player output can be denoted as follows, namely $\left\{y_{1}, x_{1}\right\},\left\{y_{2}, x_{2}\right\}$, and $\left\{y_{3}, x_{3}\right\}$. Absolute advantage can be formalized as follows: $y_{1}=\kappa y_{2}=\kappa y_{3}$ and $x_{2}=\kappa x_{1}=\kappa x_{3}$, where $\kappa \geq 1^{4}$. As each of the three players produces both goods in autarky, the resulting Cobb-Douglas utility levels (payoffs) are $U_{1}=y_{1}^{\gamma_{1}} x_{1}^{\gamma_{2}}$, $U_{2}=y_{2}^{\gamma_{1}} x_{2}^{\gamma_{2}}$, and $U_{1}=y_{3}^{\gamma_{1}} x_{3}^{\gamma_{2}}$, respectively, where $\gamma_{j}>0, \sum \gamma=1$.

To capture the gains from specialization, we assume that by specializing, output rises by a factor of $\alpha$, where $\alpha>1$. For example, if Player 1 specializes in good $\mathrm{y}$, then his output increases to $\alpha y_{1}$. However, for specialization to occur, a form of organized exchange (trading institutions) must exist. In our framework, the relevant trading institution takes the form of a specialized trader who buys, holds and sells the two goods $y_{i}$ an $x_{i}[25,26]$. For our purposes, we will assume that Player 3 has an absolute advantage in this activity (i.e. intermediation). Absolute advantage dictates that Player 1 will specialize in good $y$ and Player 2 in good $x$, Player 3 in intermediation.

For the sake of analysis, the cost of buying, holding and selling goods $y$ and $x$ will be expressed in real terms, specifically as a fraction $(1-\beta)$ where $(0<\beta<1)$ of output. For example, the cost of intermediating $\alpha y_{1}$ is $(1-\beta) \alpha y_{1}, \quad \beta \alpha y_{1}$ being the net-of-intermediationcosts quantity of good y available for exchange (i.e. between Players 1 and 2$)^{5}$. Next, we assume that the latter is shared equally among Players 1 and $2^{6}$. As such, the corresponding utility levels (payoffs) can be written as $U_{1}^{s}=\left[\beta \alpha y_{1} / 2\right]^{\gamma_{1}}\left[\beta \alpha x_{2} / 2\right]^{\gamma_{2}}$,

$U_{2}^{s}=\left[\beta \alpha y_{1} / 2\right]^{\gamma_{1}}\left[\beta \alpha x_{2} / 2\right]^{\gamma_{2}}$, and

$U_{3}^{s}=\left[(1-\beta) \alpha y_{1}\right]^{\gamma_{1}}\left[(1-\beta) \alpha x_{2}\right]^{\gamma_{2}}$, respectively.

The relevant game is as follows. Each player chooses a Nash binary strategy consisting of either the status quo/autarky $(S=0)$ or specializing $(S=1)$. Specialization and exchange (LSSE) corresponds to the case in which all three players opt for $S=1^{7}$. The game begins with the players choosing $S=0$. That is, producing and consuming goods $y$ and $x$. The question we then ask is relatively straightforward, namely, can LSSE, defined as the joint presence of specialized producers and a trader, emerge spontaneously (i.e. as Nash equilibrium)?

The corresponding payoff matrix is shown in Table 1,

${ }^{4} \kappa$, the coefficient of absolute and comparative advantage, is assumed to be the same across players and across goods. This assumption could be relaxed without loss of generality.

${ }^{5}(1-\beta) \alpha y_{1}$ and $(1-\beta) \alpha x_{2}$ represent the cost of intermediation.

${ }^{6}$ This is a simplifying assumption that can be relaxed without affecting the results.

${ }^{7}$ In this regard, the model is similar to those found in agent-based computational economics (ACE) [27]. 
where two separate subcases are presented. In the first, Player 1 chooses to not specialize. Here, we see that $S_{2}=S_{3}=0$ is the preferred strategy. If Players 2 and 3 nonetheless specialize, their utility falls to zero as there is no good y available on the market (i.e. to purchase). When Player 1 specializes (Subcase 2), specialization will be the preferred Nash strategy on the part of the two other players when $\alpha \beta \sqrt{\kappa}>2$ and $(1-\beta) \alpha \kappa>2{ }^{8}$. Put differently, for specialization to be a preferred strategy, it must be the case that specialization on the part of Players 1 and 2 more than compensates the loss of output that accompanies the creation of trade institutions, in this case, Player 3 becoming a specialized trader. It turns out that $S_{1}=S_{2}=S_{3}=0$ and $S_{1}=S_{2}=S_{3}=1$ are the only two Nash equilibria. If the three players choose autarky to begin with, then LSSE is not possible. However, if they choose specialization, LSSE emerges.

Consider the off-diagonal terms. If Players 1 and 2 choose autarky, and Player 3 chooses to specialize, then the payoffs are $y_{1}^{\gamma_{1}} x_{1}^{\gamma_{2}}, y_{2}^{\gamma_{1}} x_{2}^{\gamma_{2}}$, and 0 , respectively. Player 3 is worse off as a result. This illustrates the underlying incentive structure. Starting from a position of autarky, there are no private (Nash) incentives to specialize. Notwithstanding the case in which the players simultaneously choose to specialize initially, LSSE is unlikely in a relevant Nash game. This, however, is not the case in the corresponding cooperative-strategy game, where the three cooperate and play $S_{1}=S_{2}=S_{3}=1$ thus moving to the Pareto-dominant LSSE equilibrium.

These results are easily generalized to the case of $n+1$ players and $\mathrm{n}$ goods. In this case, LSSE will be a dominant Nash/Cooperative strategy if $\alpha \beta \kappa^{(n-1) / n}>n$ and $(1-\beta) \alpha \kappa>n$. All off-diagonal entries in the relevant $n$ +1 by $n+1$ payoff matrix will be analogous to those in Table 1. Specialization in this case has to be such that each individual producer, of which there are $n$, serves the entire market for his/her good, and the $n+1$ player becomes the specialized trader, in this case buying, holding and selling $n$ goods. To summarize, for economic complexity, defined here as $S_{1}=S_{2}=S_{3}, \cdots, S_{n+1}=1$, to emerge, two sets of conditions must be met, namely $\alpha \beta \kappa^{(n-1) / n}>n$ and $(1-\beta) \alpha \kappa>n$ (technology conditions) and coordination (coordination condition). The former refers to the various parameter values $(\alpha, \beta, \gamma, \kappa)$ while the latter refers to players' cooperative strategy (equilibria). Notwithstanding the improbable, but not impossible, Nash LSSE case, both are necessary conditions for the emergence of large scale specialization and exchange.

\footnotetext{
${ }^{8}$ These conditions were derived by equating $\left[\beta \alpha y_{1} / 2\right]^{\gamma_{1}}\left[\beta \alpha \kappa x_{1} / 2\right]^{\gamma_{2}}$ to $y_{1}^{\gamma_{1}} x_{1}^{\gamma_{2}}$, and $\left[(1-\beta) \alpha \kappa y_{3}\right]^{\gamma_{1}}\left[(1-\beta) \alpha \kappa x_{3}\right]^{\gamma_{2}}$ to $y_{3}^{\gamma_{1}} x_{3}^{\gamma_{2}}$, and solving for $\mathrm{F}(\beta, \alpha, \kappa)=0 \quad\left(\gamma_{1}=\gamma_{2}=1 / 2\right)$.
}

Table 1. Payoff matrix.

\begin{tabular}{|c|c|c|}
\hline \multicolumn{3}{|c|}{ Subcase 1: $S_{1}=0$} \\
\hline $2 \backslash 3$ & $S_{3}=0$ & $S_{3}=1$ \\
\hline$S_{2}=0$ & $y_{1}^{\gamma_{1} 1} x_{1}^{\gamma_{2}}, \quad y_{2}^{\gamma_{1}} x_{2}^{\gamma_{2}}, \quad y_{3}^{\gamma_{1}} x_{3}^{\gamma_{2}}$ & $y_{1}^{\gamma_{1} 1} x_{1}^{\gamma_{2}}, \quad y_{2}^{\gamma_{1}} x_{2}^{\gamma_{2}}, 0$ \\
\hline$S_{2}=1$ & $y_{1}^{\gamma_{1}} x_{1}^{\gamma_{2}}, 0, \quad y_{3}^{\gamma_{1}} x_{3}^{\gamma_{2}}$ & $y_{1}^{y_{1}} x_{1}^{y_{2}}, 0,0$ \\
\hline \multicolumn{3}{|c|}{ Subcase 2: $S_{1}=1$} \\
\hline $2 \backslash 3$ & $S_{3}=0$ & $S_{3}=1$ \\
\hline$S_{2}=0$ & $0, \quad y_{2}^{\gamma_{1}} x_{2}^{\gamma_{2}}, \quad y_{3}^{\gamma_{1}} x_{3}^{\gamma_{2}}$ & $0, y_{2}^{\gamma_{1}} x_{2}^{\gamma_{2}}, 0$ \\
\hline \multirow{3}{*}{$S_{2}=1$} & \multirow{3}{*}{$0,0, \quad y_{3}^{1 / 1} x_{3}^{\gamma_{2}}$} & {$\left[\beta \alpha y_{1} / 2\right]^{\gamma_{1}}\left[\beta \alpha x_{2} / 2\right]^{\gamma_{2}}$,} \\
\hline & & {$\left[\beta \alpha y_{1} / 2\right]^{\gamma_{1}}\left[\beta \alpha x_{2} / 2\right]^{\gamma_{2}}$,} \\
\hline & & {$\left[(1-\beta) \alpha y_{1}\right]^{\gamma_{1}}\left[(1-\beta) \alpha x_{2}\right]^{\gamma_{2}}$} \\
\hline
\end{tabular}

The next step is to model what we refer to as "institutional coordination" explicitly-that is, third-party coordination [23]. We have shown thus far that LSSE requires not only non-negligible productivity gains from specialization, but also the emergence of a specialized trader (Player 3) who coordinates (organizes) trade (buy, hold and sell). It is important to point out that such activities do not contribute directly to welfare (i.e. enter the utility function), but yet are nonetheless necessary. Notwithstanding the case in which LSSE emerges spontaneously (the probability of which diminishes with $n$, the number of players), large-scale coordination is also necessary. Like all other activities, it is costly. Players must establish lines of communication between themselves and decide on a set of rules for collective decision making, all of which is costly. We shall refer to such strategies on the part of players as communication and coordination strategies (CCSs). It is conceivable that these costs could tip the balance in favor of autarky. That is, CCS costs could make autarky the evolutionary stable strategy despite non-negligible gains from specialization and exchange. To model this explicitly, we now turn and model LSSE in the presence of CCS costs.

\subsection{Communication and Coordination Strategies}

Two broad types of strategies will be considered. The first are discretionary CCSs, where equilibria (e.g. $\left.S_{i} \forall i=1,2, \cdots, n\right)$ are arrived at by unanimous consent (unanimity game), and players commit ${ }^{9}$. Entry may or may not be controlled (i.e. require consent). The second are rules-based CCSs, where players, again by way of consent, unanimously adopt a set of rules that, once in place, govern behavior (i.e. $S_{i}$ ). Communication and coordination strategies (CCSs) can as such range from a

${ }^{9}$ These assumptions can be relaxed without affecting the results. For example, majority rule or any other less-than-unanimity rules could be invoked as the relevant decision criterion. 
highly unstructured decision-making unit (distributed $\mathrm{CCS}$ ) to a hierarchical management structure (e.g. hierarchical CCS), to a set of rules (e.g. rules-based CCS), or lastly, to some combination thereof.

Formally, a communication and coordination strategy provides each of the players with the necessary information and decisional framework withing which to coordinate their strategies (i.e. $S_{i}$ ) [28,29]. Drawing from simple network design theory, we assume that communication and coordination requires the establishment of a link between two players, one that allows for the exchange of information on preferences, coordination possibilities, technology and strategies. In the $n$ player case, there are a total of $[n(n-1)] / 2$ pairwise links. This describes the baseline case, namely the distributed CCS, where there are $[n(n-1)] / 2$ pairwise links. The cost function of maintaining each link is $\xi=\xi(d, m l, \sigma)$ which is increasing in $d$ is the average geographical distance between any two players (taken pairwise), $\mathrm{ml}$ is the number of goods and services $(m)$ multiplied by $l$, the average number of sub-processes per good/service, and $\sigma$, the uncertainty associated with a given technology (or new technology) ${ }^{10}$. Accordingly, the further apart players are geographically on average, the higher are communication and coordination costs. The more goods and services there are, and the more sub-processes (1) there are per good/service, the greater is the cost of communication and coordination (vertical and horizontal information flows and decision trees). The more complex is a technology (product and process), the higher is the cost of communication and coordination. Lastly, the cost of communication and coordination per link is increasing in the ex-ante uncertainty associated with a new technology. The associated uncertainty raises the costs of communication and coordination and may preempt technological change ${ }^{11}$. The corresponding average (per player) cost of communication and coordination in the distributed CCS case is $\xi(d, m l, \sigma)(n-1) / 2$. Note that in this case, the average cost increases with the group size, and with product and process uncertainty.

Consider next the case of the hierarchical CCS, where the players begin by choosing a leader (gatekeeper), referred to as the $n^{\text {th }}$ player. Once chosen, s/he coordinates information flows and decision making, going between the other $n-1$ players $^{12}$. Costs differ. First, there is the cost of choosing the coordinator/gatekeeper,

\footnotetext{
${ }^{10}$ By technology-related uncertainty, it should be understood the uncertainty associated with a given set of technologies (process and product) at any given point in time.

${ }^{11}$ Other factors affecting $\xi$, the cost of each link in a communication and coordination game are variables such as the number of rounds of negotiation required to reach an agreement, as well as the information costs per round.

${ }^{12}$ One could define the $n^{\text {th }}$ player as a clique [28]. As such, the $n^{\text {th }}$ player deals with all other $n-1$ players, providing information on preferences, actions, and reactions.
}

$\xi(d, m l, \sigma)[n(n-1)] / 2$. Then, there is the cost of communicating and coordinating in the presence of the gatekeeper, $\xi(d, m l, \sigma)[n-1]$. The cost of choosing a gatekeeper is a one-time cost; however, the cost of communicating and coordinating is a recurrent cost which, as shown, is an increasing function of $n$, the number of players ${ }^{13}$. It stands to reason that the longer the game is played, the more advantageous it is to opt for a hierarchical CCS over a distributed CCS. While the hierarchical CCS is, over time, less costly than the distributed CCS, both are discretionary forms of communication and coordination, and, as, such, relatively costly. Each new case (coordination problem) must be considered individually, and, more importantly, the outcome (equilibria) must be consensual.

The third CCS considered in this paper is a rules-based CCS, consisting of the establishment of, and execution of a set of communication and coordination rules. In this case, starting from autarky, players initially opt for either a distributed or hierarchical CCS within which a set of rules is drafted and adopted, one that could be invoked in the presence of potential coordination failures. An example of a rules-based CCS is the case of an initial resolution of the coordination failure LSSE (by fiat), followed by the implementation of a price mechanism with entry and exit, where price increases signal excess demand, and price decreases signal excess supply ${ }^{14}$. Prices and profits constitute the relevant signalling devices, coordinating the behavior of the $n$ players. Once in place, the cost of communicating and coordinating activity is relatively low, and, in the limit, zero, abstracting from enforcement costs (judicial system).

The fourth and last CCS is a hybrid, consisting of a rules-Based CCS with local hierarchies. In this case, each of the $m$ goods is produced within a vertically-integrated ( $l$ sub-processes or $l$ stages of value added), hierarchically organized producers (firms). Within the latter, communication and coordination is organized hierarchically (management structures). Examples of these include large, vertically-integrated "giant firms" [8,9].

Thus far, it has been assumed that outcomes are deterministic. That is, a CCS yields the desired outcome with certainty. While this may be true in the case of simple coordination problems (simple technology combined with limited number of players/goods/services), it may not be the case in the presence of complex problems,

\footnotetext{
${ }^{13}$ We implicitly assume that the gatekeeper (i.e. the $n^{\text {th }}$ players) does not incur any additional costs in his/her role. That is, s/he offers coordinating services for free. If we relax this assumption and assume that $\mathrm{s} /$ he has to deploy additional resources, then the resulting costs would have to be factored in on a recurrent basis.

${ }^{14}$ This is similar to market simulation exercises in artificial computational economies (ACE's), where roles (producers, merchants, consumers) are assigned initially, and are then free to transact in a market environment.
} 
where outcomes are more probabilistic. CCSs may not yield the Pareto-optimal outcome-in fact, they may fail altogether. This can result from the players' or the gatekeeper's inability to fully understand either the technology, or how the technology is best deployed. To capture this, Column 3 in Table 2 formalizes $\phi$, the probability of success as a function of $n$, the number of players, $\mathrm{ml}$, the product of the number of goods/services and the number of processes per good/service ( $l$ ), and $\sigma$, the overall, aggregate complexity of the technology. Note that the probability of success in the case of discretionary CCSs (distributed and hierarchical) is decreasing in both $n, m l$ and $\sigma$. Contrast this with rules-based CCSs, where it is decreasing only in $\mathrm{ml}$ and $\sigma$. Rules-based CCSs are, as we will attempt to show, better suited to more complex environments. This is not to say, however, that success is assured. A rules-based CCS is only as good as the elements that comprise it. If players are unable to fully appreciate a technology's potential (i.e. $\alpha$ ), then it may not be adopted.

The choice of an initial CCS within which to adopt a set of rules will be determined by, among other factors, the very nature of the problem (i.e. simple or complex). For example, in the case of potentially complex phenomena, a rules-based CCS would minimize costs. That is, starting from a distributed CCS, they designate a gatekeeper (i.e. the $n^{\text {th }}$ player), and proceed to draft a set of rules governing the eventual rules-based CCS. In this case, the hierarchical CCS is transitional in nature, existing for the sole purpose of setting up rules and resolving any initial coordination failures. Analytically, the overall costs of setting up a rules-based CCS consist of $\xi(d, m l, \sigma)[n(n-1) / 2]$, the cost of the initial distributed CCS, and $\xi(d, \sigma)[n-1]$, the cost of establishing rules within the hierarchical $\mathrm{CCS}^{15}$. We assume that $\xi(d, n)$ is considerably greater than $\xi(d, m l, \sigma)$, given the nature of the task at hand, namely, establishing rules. Put differently, the establishment of rules is more communication and coordination intensive than establishing a simple coordination strategy (i.e. within the context of a one-shot coordination game).

Discretion-based CCSs and rules-based CCSs differ also in so far as strategic behavior is concerned. In a discretion-based CCS, coalitions and strategic behavior are possible. As decisions are consensual, strategic behavior is possible. Players may resist change, whether it be entry of new members, or a change in a member's behavior $^{16}$. For example, a coalition of players can block the introduction of a new technology that would potentially decrease the value of their assets. Such behavior cannot, however, arise in rules-based CCS.

Table 2 summarizes the costs as well as the risks associated with the four CCSs described here. We see, for example, that the distributed CCS has no initial (i.e. fixed) costs, but high recurrent costs. This owes to the lack of a structured environment. These costs are lower in the hierarchical CCS case. It, however, requires an initial fixed cost of $\xi(d, m l, \sigma)[n(n-1) / 2]$, to choose a "coordinator." Recurrent communication and coordination costs are zero in the case of the rules-based CCS. The initial costs of the latter, however, are greater than either of the two discretionary CCSs. Lastly, rules-based CCSs with local hierarchies have recurrent communication and coordination costs (i.e. the cost of large-scale organizational hierarchies-Alfred Chandler's visible hand"), defined as $\kappa(l) q$, where $\kappa(l)$ corresponds to the cost of a management hierarchy in the presence of $l$ sub-processes, and $q$ corresponds to the number of local hierarchies (i.e. giant firms)[30].

The problem of the emergence and evolution of economic complexity (LSSE) in the presence of risky and costly communication and coordination strategies is formalized in terms of a communication and coordination cost-augmented payoff matrix, the diagonal elements of which are shown in Table 3 , where $\delta$ corresponds to the cost, expressed in terms of the $n$ goods of the relevant communication and coordination strategy for the $n+1$ players $^{17}$. Clearly, the lower is $\delta$, ceteris paribus the greater the probability that LSSE will emerge as an evolutionary stable strategy. We see that LSSE is

Table 2. Initial and recurrent CCS costs and probability of success.

\begin{tabular}{cccc}
\hline CCS $\backslash$ Type & Initial & Recurrent & Probability $(\phi)$ \\
\hline Distributed & 0 & $\xi(d, m l, \sigma)[n(n-1)] / 2$ & $1 / \mu(n, m l, \sigma)$ \\
Hierarchical & $\xi(d, m l, \sigma)[n(n-1)] / 2$ & $\xi(d, m l, \sigma)[n-1]$ & $1 / \mu(n, m l, \sigma)$ \\
Rules-Based & $\xi(d, m l, \sigma)[n(n-1)] / 2+\xi(d, \sigma)[n-1]$ & 0 & $1 / \mu(m l, \sigma)$ \\
Rules-Based with Local Hierarchies & $\xi(d, m l, \sigma)[n(n-1)] / 2+\xi(d, \sigma)[n-1]$ & $\kappa(l) q$ & $1 / \mu(m l, \sigma)$ \\
\hline \hline
\end{tabular}

${ }^{15}$ This is analogous to the January 2005 election in Iraq, the stated purpose of which was to elect a slate of candidates who, once in office, would begin drafting a new constitution.

${ }^{16} \mathrm{~A}$ good example of such coalitions is the early $19^{\text {th }}$ century British House of Lords which voted against free-trade.

${ }^{17}$ Here, it is implicitly assumed that CCS costs are assumed equally by all players. Affecting such costs are the cost of communication and the costs of coordination. The lower are such costs, the lower is $\delta$ and the greater is the probability that LSSE emerges as the relevant equilibria. 
Table 3. Diagnonal elements of the CCS-augmented payoff matrix.

\begin{tabular}{ll}
\hline$S_{1}=S_{2}=\cdots=S_{n+1}=0$ & $\prod_{i=1}^{n} y_{1 i}^{\gamma_{i}}, \prod_{i=1}^{n} y_{1 i}^{y_{i}}, \cdots, \prod_{i=1}^{n} y_{1 i}^{y_{n+1}, i}$ \\
& $\phi \prod_{i=1}^{n}\left[(1-\delta) \beta \alpha y_{i i} / n\right]^{\gamma_{i}}$, \\
$S_{1}=S_{2}=\cdots=S_{n+1}=0$ & $\phi \prod_{i=1}^{n}\left[(1-\delta) \beta \alpha y_{i i} / n\right]^{\gamma_{i}}, \cdots$, \\
& $\phi \prod_{i=1}^{n}(1-\delta)(1-\beta) \alpha y_{i i}^{\gamma_{i}}$
\end{tabular}

most likely to emerge when $\alpha$, the specialization coef ficient is high, $\delta$, the cost of communication and coordination is low, and $\phi$, the probability of success, is high. An $\alpha$-augmenting technology shock will, in the presence of a low $\delta$, be economic-complexity increasing, and vice-versa. The effect of $\beta$, the cost of intermediation, on LSSE is ambiguous, at least in terms of the payoff matrix. A higher price of intermediation will increase the payoff to the $n+1$ player (i.e. the merchant) vis-à-vis the autarky payoff, but reduce the payoff to would-be producers (specialized), thus possibly reducing the probability of LSSE. The more complex is the coordination problem, the lower is $\phi$, and the less likely is it to emerge as a solution to the relevant game. Within this framework, there exists the very real possibility that new, potentially-revolutionary, output-increasing technologies are not adopted owing to prohibitive communication and coordination costs. Communication acts as a constraint on coordination and, in turn, coordination acts as a constraint on adoption. Conceivably, the overall cost of communication and coordination could be such that economic complexity fails to emerge in the presence of Pareto-improving technological change.

\section{LSSE: The Historical Record}

These results provide a convenient framework within which to reexamine the question raised by Hicks, namely what prompted the emergence and evolution of economic complexity, defined as large-scale specialization and exchange (LSSE)-specialization upon trade. In this section, we examine three cases (periods): the rise of civilization in Mesopotamia, the first industrial revolution and the second industrial revolution. We begin with the case of Mesopotamia, the cradle of civilization, the defining features of which were i) the presence of a large-scale agriculture (irrigation, draft animals) and manufactures (specialized artisans) and ii) the presence of specialized traders and trading institutions (temples and ziggurats) and iii), the presence of hierarchical political governance (religious authorities) [31-34]. The relevant question is how did LSSE emerge in the Tigres and Euphrates valley in the fourth millennium before the modern era? Chro- nologically, which came first, the technology $(\alpha)$ or the temples and ziggurats $(\beta, \delta)$ ? Did the emergence of a new technology lead to a new CCS, or vice versa?

There are a number of possibilities. For example, the development of large-scale religion (ziggurats and priests) by providing the necessary CCS, led to the development of large-scale agriculture, leading to the ensuing economic complexity. Or conversely, the development of religion, by providing the necessary CCS, allowed for the application of an existing (known) technology, namely large-scale agriculture. In other words, the technology of large-scale agriculture predated the fourth millennium, but was not implemented for lack of the necessary CCS. Another possibility is that the development of agriculture (i.e. technology shock) contributed to the development of a CSS in the form of large-scale religion (ziggurats and priests). Causality in this case runs from the technology shock to the organization shock. The last possibility has the development of agriculture providing the necessary impetus for the application of an existing technology in the form of large-scale religion.

Of the four, the second appears to be the most likely, namely that the development of large-scale religion (organization) provided the necessary CCS for the application of what was then a known technology in the form of large-scale agriculture. There is considerable evidence that basic agricultural techniques (sowing, cultivating, and reaping) predated Mesopotamia by a number of millennia [35]. On the other hand, while religion predated Mesopotamia by millennia, there is no archaeological evidence of large-scale religion (i.e. large temples/ziggurats) in the upper-Paleolithic era).

What is clear from our model is that large-scale agriculture (LSSE) required large-scale religion (CSS), and large-scale religion required large-scale agriculture. In addition to providing religious services on a large scale, the temple priests of Mesopotamian cities (e.g. Sumer, Akkad) provided the necessary communication and coordination strategy (CCS) and trade institutions (specialized traders), thus lowering both $\beta$, and $\delta$, the cost of intermediation and the cost of communication and coordination, respectively, and raising $\phi$, the probability of success. Evidence of the integral role of the temple in the economic affairs (e.g. record keeping, writing, weights and measures, money, and codified civil law) of Mesopotamian cities is well documented $[33,36,37]^{18}$. Next, we examine the evolution of economic complexity defined as the continued specialization and exchange in response to technology shocks. We will be particularly interested in two well-known technology shocks (general

\footnotetext{
${ }^{18}$ Anecdotally, we know that virtually all great civilizations were literally and figuratively built around religion, in the form of temples. Large-scale temples, specialization and exchange appear to go hand-in-hand.
} 
purpose technologies), namely the steam engine (first industrial revolution) and the electric motor (second industrial revolution), each of which contributed to increasing economic complexity [38,39].

The Neolithic era witnessed a paradigm shift in the level of economic complexity, characterized by LSSE. Exchange became a staple in the cities of Mesopotamia, Egypt, China, India, Greece, and Rome. However, it was nonetheless limited. Not all wealth (goods and services) was traded [40]. In the $17^{\text {th }}$ century Great Britain, the bulk of economic activity was autarkic in nature, consisting mainly of small-scale, self-sufficient agriculture. Like in other European countries at the time, there did, nonetheless, exist, a more evolved form of economic activity, commonly referred to as mercantilism, which consisted of small-scale specialization and exchange, organized and controlled, for the most part, by government. Licences (rights) to produce and to trade were issued by royal edict, as were prices.

While allowing for a certain degree of complexity, this CCS proved, in time, to be unworkable, and the underlying cause of a shift to a new CCS, namely laisser-faire. Laisser-faire, we shall argue, was a response not to the shortcomings of mercantilism per se, but, rather, to the shortcomings of mercantilism in the presence of a paradigm technology shock in the form of the steam engine. The steam engine provided the potential for heightened economic complexity (i.e. an increase in $\alpha$ and a decrease in $\beta$ ). Factories would replace what at the time was small-scale, artisanal production (putting-out system), resulting in a manifold increase in potential output estimated by Robert Owen estimated the order of magnitude to be 40, David Ricardo, to be 20 [41,42]. Railroads reduced transportation costs, thus lowering $\beta$. Greater economic complexity was now feasible. What's more, while innovations in the Neolithic era had increased output in a handful of sectors (tool making, agriculture), the steam engine offered the possibility of increased output in many sectors of the economy [43].

Could Great Britain in the late $18^{\text {th }}$ century make the transition to the new, higher LSSE equilibrium? More to the point, could it make the transition within a hierarchical CCS? Could the Lords, Monarchy, and Prime Minister coordinate the implementation of the new process technology, one characterized by a far greater division of labor (higher l), massive investment in capital equipment, increased coordination between the stages of production (division of labor), and a more extensive distribution (sales) network. Technically, the cost of coordination skyrocketed. Referring to Table 2, greater values for $n, m$ and $l$, increases the recurrent cost of discretionary, hierarchical CCS. Add to this the uncertainty associated with the new technology and stakeholder iner- tia (i.e. the various workers' guilds opposed mechanization) and you get a tenuous outcome.

This contributed to a shift to a rules-based CCS in the form of laisser-faire. Rules as opposed to discretion, its architects argued, would guide resource allocation. Entry and exit would be free-in the sense of free of government. Output and pricing decisions would be made by the "market." Risk and uncertainty would be assumed by investors and entrepreneurs. This is not to say that all potentially-viable output and exchange opportunities would be realized, but rather that the probability that they would be realized would be greater [44]. If for some reason no one is willing to bring a new process or product to market, then even laisser-faire will fail. In this sense, free markets are a necessary, but not sufficient condition.

This, we argue, helps explain the preponderant role assigned to the entrepreneur in both classical and neo-classical political economy. The success or failure of a new technology (product and/or process) depends on his/her ability, on his/her vision, on his/her propensity to take risks. In a rules-based CCS, the entrepreneur is the key cog, whereas in a hierarchical CCS, it is the gatekeeper (e.g. government). The classics and neoclassics opined that the former outperformed the latter, without, however, actually proving it. The transition to laisser faire in Great Britain was not seamless. Hierarchical coordination was not abandoned altogether in favor of markets and entrepreneurs as evidenced by the continued presence of large, vertically-integrated firms. The British East India Company and the Hudson's Bay Company are cases in point. Clearly, in these cases, discretion-based hierarchical coordination must have dominated rulesbased laisser-faire; otherwise, such companies would have been dismantled, and sold off. Metaphorically, the visible hand gave way to the invisible hand directing atomistic as well as highly-integrated firms, the latter being internally-coordinated [49].

This brings us to the second technology shock, namely the electric motor (second industrial revolution). The development of economically-viable electro-magnetic power ushered in yet another era of heightened economic complexity. Unlike the steam engine that merely increased throughput rates and lowered unit costs and prices, electro-magnetic power witnessed the development of a whole new set of goods, goods that were electro-magnetic power based. Examples include refrigerators, vacuums, washer and dryers, radios, automobiles (affordable) [39]. Potential wealth increased manifold, as did the underlying CCS uncertainty (i.e. $\sigma$ ). Discretionary CCS costs would be prohibitive, and the probability of success (i.e. $\phi$ ) would be low. Rules-based CCS costs would be lower; however, the probability of 
success (i.e. $\phi$-Column 3 in Table 3) would nonetheless be low.

The reason is twofold. The introduction of the many new products and processes made possible by electromagnetic power introduced another Schelling-type producer-merchant coordination game, involving consumer durables. Take, for example, mass-produced automobiles. Who would sell them-the general stores of the time? Without suitable points of sale (i.e. markets), firms could not exploit the economies of scale $(\alpha)$ made possible by electro-magnetic power [45]. For example, the Ford Motor Company's Highland Park plant had a rated capacity of roughly one million automobiles per year. Also, most these new consumer durables required servicing. New sales technologies were required (e.g. dealerships), technologies that were a sine quo non of the second industrial revolution. As it turns out, the underlying coordination game (producer-merchant) was solved by the firms themselves as durable good producers established networks of dealerships to sell and service their products. Second, the resulting manufacturing processes (extremely high-throughput) required greater up-stream and downstream coordination. Feedstocks and intermediate product flows had to be carefully coordinated. Upstream suppliers had to invest massively in the new process technology (electric-powered dynamos). As the historical record bears witness, the market was unable to provide the necessary communication and coordination (CCS), which prompted the emergence of localized hierarchies in the form of highly vertically-integrated firms [8,9]. Companies such as Ford, General Motors, General Electric, Singer, and others opted for localized hierarchies. Ford Motor Company and General Electric integrated both upstream and down, setting up their own dealerships, complete with financing options (e.g. consumer credit). Again, the point is that without these localized hierarchies set against the backdrop of a rules-based CCS (markets), the second industrial revolution may not have gotten off the ground.

\section{Discussion}

Historically, the shift from a discretionary CCS (mercantilism) to a rules-based CCS (free markets), and back to what essentially are local hierarchies $[8,9]$ in the form of large, highly-integrated, multi-unit firms, we maintain, was motivated primarily by what we refer to as coordination of complexity efficiency considerations than by basic allocative efficiency considerations. The principal challenge facing the late $18^{\text {th }}$ century Great Britain was realizing the heightened economic complexity and wealth that was synonymous with the steam engine. Likewise, the principal challenge facing the early $20^{\text {th }}$ century United States was realizing the heightened economic complexity and wealth that was synonymous with electro-magnetic power (process and product technologies).

Failure to tailor the CCS to the corresponding technology complexity can be costly, as evidenced by Britain's failure in the late $19^{\text {th }}$ century to implement what was a home-grown technology, namely electro-magnetic power. The basic research on electro-magnetism and hence, the electro-magnetic motor-was carried out in the $19^{\text {th }}$ century Great Britain by such notables as Michael Faraday, Charles Wheatstone, Lord Kelvin, Joseph Swan and others. However, for a number of reasons, the British failed to implement this new technology, something that was carried out by Thomas A. Edison and George Westinghouse in the United States. The Coal Conservation Sub-Committee, set up by Viscount Haldane in 1916, made numerous references to this "puzzle." What had gone wrong? Why had the British failed to capitalize on what was a home-grown technology. In the same year, the Board of Trade struck an Electrical Trades Committee, whose given purpose was to investigate the position of the electrical trades after the war. Sir Henry Self and Elizabeth Watson summarized its findings as follows:

Reference was made in no uncertain terms to the crippling handicaps of the local and political considerations which had prevented Great Britain from reaping the fruits of the outstanding preeminence which it had received in original constructive research and development of electricity generation at the hands of pioneers such as Faraday, Wheatstone, Kelvin, Swan, Hopkinson, and many others. The loss of that outstanding lead, the history of industry in the intervening years, and the evidence taken during their examination of the position led the Committee to the following conclusions. [46,35]

In other words, local regulation, specifically by the gas and coal industry, had thwarted the development of the electric power industry in Great Britain. Rules-based laisser-faire would have, as it did in the United States, allowed for the presence of both technologies, with the spoils going to the winner.

Our results also provide a rationalization of the ex deus machina, view of the market-that is, of the market as an intelligent being-as the optimality of a rulesbased CCS in a dynamic, complex setting, one characterized by on-going technological change (process and product). As was the case in late $19^{\text {th }}$ century Great Britain, there may exist a set of processes/products whose value escapes the grasp of officials (i.e. discretionary CCSs). In such cases, the communication and coordination necessary for its implementation is best left to the "specialists"- they are the private individuals who have 
more information than the $n$ players and gatekeeper in the hierarchical CCS. A good example of this is FedEx, the brainchild of Yale undergraduate economics student Frederick Smith who in the 1960s outlined the idea of an overnight parcel-delivery service in a term-paper. His professor, legend has it, didn't see much merit in the idea, and gave him a $\mathrm{C}+$. The rest is "history", so to speak.

Our results also bring into focus many of the issues raised in the recent institutions-growth literature. This literature examines the relationship between institutions and economic growth. For example, [47-52] show causality running from limited government to economic growth, while $[53,54]$ show it running in the opposite direction. [5] provided empirical support for this view using data on urbanization of European regions during the last millennium, which showed faster city growth under more limited governments. Unfortunately, the microfoundations of this literature-that is, the underlying mechanics-are not well developed. Just how institutions affect growth is not well understood. Our work provides a framework for understanding the mechanics of governance as it relates to economic complexity, and hence growth. For example, we showed that the key factor in so far as economic complexity is concerned is not limits on executive power per se, but rather the limits of executive power (i.e. the hierarchical CCS) to communicate and coordinate. There is nothing inherently flawed with executive power; however, as shown, executive power is limited, both in its ability to understand new technologies, as well as in its ability to manage complexity. While it is not impossible for a hierarchical CCS to communicate and coordinate effectively, thus fostering economic complexity, it is less likely, especially for high values of $\sigma$, the complexity of the overall communication and coordination problem. In general, for high values of $\sigma$, the less hierarchical is the CCS, the more likely is economic complexity, and hence, economic growth. This is not to say that economic complexity cannot arise in a dictatorship; however, the likelihood of such an occurrence is low as s/he would have solve multidimensional communication and coordination problems. Historically, such occurrences have been few and far between.

\section{Summary and Conclusions}

Economic complexity has for the most part been studied at the firm level, where the emphasis has been on production process complexity, specifically, on the division of labor. In this paper, we examined the question of economic complexity, which was defined in terms of LSSE, focusing on technological change and communication and coordination costs. Interestingly, our findings are analogous. Communication and coordination costs act as a constraint on societies as a whole, hampering in some cases, preventing in others increases in economic complexity made possible by technology shocks. We maintain that this problem was at the heart of Adam Smith's magnum opus, An Inquiry into the Nature and Causes of the Wealth of Nations, published over two centuries ago. Getting in the way of increased specialization at the time (economic complexity) was the extent of the market. What ensued was an often acrimonious debate over laisser faire-that is over free markets. As we have attempted to show in this paper both communication and coordination strategies (discretion-based and rules-based) had their merits and their costs. Discretion-based CCSs, however, have performed rather poorly in the presence of new technologies.

While discretion-based CCSs (distributed and hierarchical) played an integral role in the emergence and early evolution of economic complexity, their usefulness had waned considerably by the $19^{\text {th }}$ century. Attempts at designing discretion-based CCS-based industrial societies have, not surprisingly, met with little success. Examples of such societies include the $19^{\text {th }}$ century France, the $20^{\text {th }}$ century Soviet Union, and Communist China. Based largely on the writings of Claude Rouvroy, Comte de St-Simon, the early $19^{\text {th }}$ century France, led by Napoleon, embarked on an ambitious program of industrialization organized around a hierarchical CCS. The resulting technocracy would, in St-Simon's eyes, close the gap with Great Britain, and in the process increase economic complexity. The Soviet Union and China held similar ambitions. The results are there for all to see. Hierarchical CCSs have underperformed, relative to comparable rules-based CCSs, owing to, among others factors, high information, communication and coordination costs.

As we have attempted to show in this paper, technology and technological change are not sufficient conditions for heightened economic complexity and material wealth. As with all other forms of complexity, organization is of equal importance. Heightened specialization and trade require cost-efficient, highly effective CCSs. The latter ranged from discretionary CCSs to rules-based CCSs to combination discretionary-rules-based CCSs. When it comes to CCSs, no one CCS dominates all others. Early innovations in economic complexity were the result of discretionary, hierarchical CCSs. In time, these proved to be too costly and ineffective, prompting a shift to rules-based CCSs in the form of free markets. The shortcomings (efficiency-wise) of markets, in turn, prompted the emergence of a hybrid CCS in the form of localized hierarchies-rules-based CCSs, with large vertically-integrated firms operating in what are free-markets. These results are interesting for a number of reasons. First and foremost is their synthetic nature. The theory of 
economic complexity presented in Sections 2 and 3 synthesizes over two hundred years of political economy and 6000 years of economic complexity. In doing so, they refocus the debate surrounding "economic systems" around dynamic considerations, notably the ability to coordinate "potential" economic complexity. An interesting by-product is a theory of the origins of large-scale specialization and exchange (LSSE) as equilibrium to a Schelling-type coordination game. More often than not, LSSE required discretionary CCSs, a fact history bears witness to.

The study of economic complexity is in its infancy. Much work remains to be done, particularly on CCSs and their various attributes (costs, efficiency). Another interesting offshoot is the evolution of CCSs. How did they evolve over time? What were the underlying issues, and politics? As it turns out, the history of economic thought is intimately tied to CCS evolution, with the shift to rules-based laisser-faire being the equivalent in economics of the big-bang in paleontology.

\section{References}

[1] S. Durlauf, "What Should Policymakers Know About Economic Complexity?" Working Paper for the SFI Economics Research Program, 97-10-080, Santa Fe Institute, Santa Fe, 1997.

[2] B. C. Beaudreau, "Energy and the Rise and Fall of Political Economy," Greenwood Press, Westport, 1999.

[3] M. Berg, "The Machinery Question and the Making of Political Economy," Cambridge University Press, Cambridge, 1980.

[4] E. Glaeser, R. La Porta, F. Lopez-de-Silanes and A. Shleifer "Do Institutions Cause Growth?" Journal of Economic Growth, Vol. 9, No. 3, 2004, pp. 271-303. doi:10.1023/B:JOEG.0000038933.16398.ed

[5] R. la Porta, F. Lopez-de-Silanes, R. Vishny and A. Shleifer, "Law and Finance?" Journal of Political Economy, Vol. 106, No. 6, 1998, pp. 271-303.

[6] T. Schelling, "The Strategy of Conflict," Harvard University Press, Cambridge, 1960.

[7] A. Smith, "An Inquiry into the Nature and Causes of the Wealth of Nations," Encyclopaedia Britannica, Chicago, 1990 (1776).

[8] A. Chandler, "The Visible Hand: The Revolution in American Management," Harvard University Press, Cambridge, 1977.

[9] R. Sobel, "The Age of Giant: A Microeconomic History of American Business 1914-1970," Greenwood Press, Westport, 1972.

[10] R. Coase, "The Nature of the Firm," Economica, Vol. 4, No. 16, 1937, pp. 386-405. doi:10.1111/j.1468-0335.1937.tb00002.x

[11] O. Williamson, "The Economic Institutions of Capitalism: Firms, Markets and Relational Contracting," Free Press,
New York, 1985.

[12] R. Langlois, "The Vanishing Hand: The Changing Dynamics of Industrial Capitalism," Industrial and Corporate Change, Vol. 12, No. 2, 2003, pp. 351-385. doi:10.1093/icc/12.2.351

[13] G. Becker and K. Murphy, "The Division of Labor, Coordination Costs, and Knowledge," The Quarterly Journal of Economics, Vol. 107, No. 4, 1992, pp. 1137-1160. doi: $10.2307 / 2118383$

[14] M. Thomassen and M. Lorenzen, "The Dynamic Costs of Coordination and Specialization: Production Activities and Learning Processes in the Danish Construction and Furniture Industries," Working Paper, Copenhagen Business School, 2001.

[15] T. van Zandt, "Decentralized Information Processing in the Theory of Organizations," In: M. Suriel, ed., Contemporary Economic Development Reviewed, Vol. 4: The Enterprise and Its Environment, MacMillan Press, London, 1997.

[16] R. P. Gilles and D. Diamantaras, "To Trade or Not to Trade: Economies with a Variable Number of Tradeables," International Economic Review, Vol. 44, 2003, pp. 1173-1204. doi:10.1111/1468-2354.t01-1-00105

[17] R. P. Gilles and D. Diamantaras, "On the Microeconomics of Specialization," Journal of Economic Behavior and Organization, Vol. 55, No. 2, 2004, pp. 223-236. doi:10.1016/j.jebo.2003.07.007

[18] X. K. Yang and Y. K. Ng, "Specialization and Economic Organization: A New Classical Micro-Economic Framework," North-Holland, Amsterdam, 1993.

[19] X. K. Yang, "Economics: New Classical Versus Neoclassical Frameworks," Blackwell Publishing, Malden, 2001.

[20] J. Greenwood and B. D. Smith, "Financial Markets in Development, and the Development of Financial Markets," Journal of Economic Dynamics and Control, Vol. 21, 1997, pp. 145-181. doi:10.1016/0165-1889(95)00928-0

[21] R. Kranton, "Reciprocal Exchange: A Self-Sustaining System," American Economic Review, Vol. 86, No. 4, 1996, pp. 130-151.

[22] J. Hicks, "A Theory of Economic History," Oxford University Press, London, 1969.

[23] R. Cooper, D. van DeJong, R. Forsythe and T. W. Ross, "Communication in Coordination Games," Quarterly Journal of Economics, Vol. 107, No. 2, 1992, pp. 739771. doi: $10.2307 / 2118488$

[24] J. V. Huyck, R. Battalio and R. Beil "Tacit Coordination Games, Strategic Uncertainty, and Coordination Failure," American Economic Review, 1990, pp. 234-248.

[25] P. Howitt and R. Clower, "The Emergence of Economic Organization," Journal of Economic Behavior and Organization, Vol. 41, No. 1, 2000, pp. 55-84. doi:10.1016/S0167-2681(99)00087-6

[26] R. Starr and M. Stinchcombe, "Exchange in a Network of Trading Posts," In: G. Chichilnisky, Ed., Markets, Information and Uncertainty: Essays in Economic Theory in 
Honor of Kenneth J. Arrow, Cambridge University Press, Cambridge, 1999.

[27] J. M. Epstein and R. Axtell, "Growing Artificial Societies: Social Sciences from the Bottom up," MIT Press, Cambridge, 1996.

[28] M. Chwe, "Communication and Coordination in Social Networks," Review of Economic Studies, Vol. 67, 2000, pp. 1-16. doi:10.1111/1467-937X.00118

[29] M. Chwe, "Rational Ritual: Culture, Coordination, and Common Knowledge," Princeton University Press, Princeton, 2001.

[30] P. Bolton and M. Dewatripoint, "The Firm as a Communication Network," Quarterly Journal of Economics, Vol. 109, No. 4, 1994, pp. 809-839. doi:10.2307/2118349

[31] H. Crawford, "Sumer and the Sumerians," Cambridge University Press, Cambridge, 1991.

[32] L. M. Dudley, "The Word and the Sword How Techniques of Information and Violence Have Shaped Our World," Basil Blackwell, Malden, 1991.

[33] L. A. Oppenheim, "Ancient Mesopotamia, Portrait of a Dead Civilization," University of Chicago Press, Chicago, 1964.

[34] M. Silver, "Economic Structures of Antiquity," Greenwood Press, Westport, 1995.

[35] L. Cavalli-Sforza and F. Cavalli-Sforza, "The Great Human Diasporas: The History of Diversity and Evolution," Addison-Wesley, New York, 1996.

[36] F. Meijer and O. van Nijf, "Trade, Transport and Society in the Ancient World," Routledge, London, 1992.

[37] D. Schmandt-Besserat, "An Archaic Recording System and the Origin of Writing," Syro-Mesopotamian Studies, 1977, pp. 1-31.

[38] E. Helpman, "General Purpose Technologies and Economic Growth," MIT Press, Cambridge, 1998.

[39] E. Helpman and M. Trajtenberg, "A Time to Sow and a Time to Reap: Growth Based on General Purpose Technologies," National Bureau of Economic Research Working Paper No. 4854, 1995.

[40] P. Garnsey, K. Hopkins and C. R. Whittaker, "Trade in the Ancient Economy," University of California Press, Berkeley, 1983.

[41] R. Owen, "A New View of Society and Other Writings," J. M. Dent and Sons Ltd., London, 1820 (1927).

[42] D. Ricardo, "On the Principles of Political Economy and
Taxation,” John Murray, London, 1817.

[43] J. H. Clapham, "An Economic History of Modern Britain," Cambridge University Press, Cambridge, 1926.

[44] J. A. Schumpeter, "The Theory of Economic Development," Harvard University Press, Cambridge, 1951.

[45] B. C. Beaudreau, "Mass Production: The Stock Market Crash, and the Great Depression: The Macroeconomics of Electrification," Greenwood Press, Westport, 1996.

[46] H. Self and E. M. Watson, "Electricity Supply in Great Britain," Allen and Unwin, London, 1952.

[47] D. Acemoglu, S. Johnson and J. A. Robinson, "The Colonial Origins of Comparative Development: An Empirical Investigation," American Economic Review, Vol. 91, No. 5, 2001, pp. 1369-1401. doi:10.1257/aer.91.5.1369

[48] D. Acemoglu, S. Johnson and J. Robinson. "The Rise of Europe: Atlantic Trade, Institutional Change, and Economic Growth," American Economic Review, Vol. 95, No. 3, 2005, pp. 546-579. doi:10.1257/0002828054201305

[49] D. Dollar and A. Kraay, "Institutions, Trade and Growth," Journal of Monetary Economics, Vol. 50, No. 1, 2003, pp 133-162. doi:10.1257/0002828054201305

[50] W. Easterly and R. Levine, "Tropics, Germs, and Crops: How Endowments Influence Economic Development," Journal of Monetary Economics, Vol. 50, No. 1, 2003, pp. 3-39. doi:10.1016/S0304-3932(02)00200-3

[51] R. E. Hall and C.I. Jones, "Why Do Some Countries Produce so Much More Output per Worker than Others?" Quarterly Journal of Economics, Vol. 114, No. 1, 1999, pp. 83-116. doi:10.1162/003355399555954

[52] D. Rodrik, A. Subramanian and F. Trebbi, "Institutions Rule: The Primacy of Institutions over Geography and Integration in Economic Development," NBER Working Paper 9305, National Bureau of Economic Research 2002.

[53] M. Alvarez, J. A. Cheibub, F. Limongi and A. Przeworski, "Democracy and Development: Political Institutions and Material Well-Being in the World, 1950-1990," Cambridge University Press, Cambridge, 2000.

[54] R. J. Barro, "Determinants of Democracy," Journal of Political Economy, Vol. 107, No. 2, 1999, pp. 158-183. doi:10.1086/250107

[55] J. B. DeLong and A. Shleifer, "Princes and Merchants: City Growth before the Industrial Revolution," Journal of Law and Economics, Vol. 36, No. 2, 1993, pp. 671-702. doi:10.1086/467294 